\title{
Game method for modelling with temporal intuitionistic fuzzy evaluations for locating the wildfire ignition point
}

\author{
Veselina Bureva $^{1}$, Lilija Atanassova ${ }^{2}$ and Krassimir Atanassov ${ }^{3}$ \\ ${ }^{1}$ Intelligent Systems Laboratory, Department of Computer Systems and Technologies \\ Faculty of Technical Sciences, "Prof. Dr. Asen Zlatarov" University \\ 1 "Prof. Yakimov" Blvd., 8010 Burgas, Bulgaria \\ e-mail: vbureva@btu.bg \\ ${ }^{2}$ Institute of Information and Communication Technologies \\ Bulgarian Academy of Sciences, \\ Acad. G. Bonchev St., Block 2, 1113 Sofia, Bulgaria \\ e-mail: 1 .c.atanassova@gmail.com \\ ${ }^{3}$ Department of Bioinformatics and Mathematical Modelling \\ Institute of Biophysics and Biomedical Engineering \\ Bulgarian Academy of Sciences, \\ Acad. Georgi Bonchev Str., Block 105, 1113 Sofia, Bulgaria \\ e-mail: krat@bas.bg
}

\begin{abstract}
The concept of a temporal intuitionistic fuzzy pair is introduced. It is used for an evaluation of the results of a Game Method for Modelling applied over some areas of fire in a two-dimensional orthogonal grid of cells.
\end{abstract}

Keywords: Game method for modelling, Forest fire, Intuitionistic fuzzy set, Temporal intuitionistic fuzzy pair.

2010 Mathematics Subject Classification: 03E72. 


\section{Introduction: The concept of a temporal intuitionistic fuzzy pair}

First, here, for a first time, we introduce the concept of a Temporal Intuitionistic Fuzzy Pair (TIFP) and after this, we will illustrate it, applying this new object for evaluation of the results of the Game Method for Modelling (GMM, see [1]).

Let $T=\left\{t_{1}, t_{2}, \ldots\right\}$ be a fixed time-scale with finite (in the present research) or infinite number of elements. Let $E$ be a fixed universe. The standard Intuitionistic Fuzzy Set (IFS, see [2,3] is defined as the object with the form

$$
A=\left\{\left\langle x, \mu_{A(x),}, \nu_{A(x)}\right\rangle \mid x \in E\right\} .
$$

In $[2,3]$, the object

$$
A(T)=\left\{\left\langle\langle x, t\rangle, \mu_{A(x, t)}, v_{A(x, t)}\right\rangle \mid x \in E \& t \in T\right\}
$$

is defined as a Temporal Intuitionistic Fuzzy Set (TIFS).

In [6], the object $x=\langle a, b\rangle$, where $a, b \in E$ and $a+b \leq 1$ is called an Intuitionistic Fuzzy Pair (IFP). By analogy with the last two concepts, here, we define the concept of a TIFP by: $x(t)=\langle a(t), b(t)\rangle$, where $a(t), b(t) \in E$ and $a(t)+b(t) \leq 1$, where $t \in T$ (the defined above time-scale).

Therefore, for a fixed IFS $\langle a, b\rangle$, we can define the set of TIFPs by:

$$
B(T)=\{\langle x(t), a(t), b(t)\rangle \mid t \in T\}
$$

and obviously, this set is an ordinary IFS with universe $T$. The TIFPs have all properties of the standard IFPs, described in [4]. Below, we illustrate the way of use of the TIFPs with an example related to the GMM.

\section{Game method for modelling}

The GMM is a modification of the Conway's Game of Life (CGL). Conway's Game of Life (CGL) is introduced by John Conway in 1970 as a cellular automaton. A cellular automaton is made of a grid of cells in which finite number of states can be assigned. Each cell has a set of its neighborhood cells. CGL's "universe" is an infinite two-dimensional orthogonal grid of square cells. The cells have two possible states "alive" or "dead". The cells in the grid interact with its eight neighbors, placed vertically, horizontally or diagonally. Many variations of the presented rules exist and different combinations of numbers for live and died cells are also known in the literature. Game Method for Modelling is an extension of CGL. The following series of papers present the theory and applications of the GMM [1-5, 7, 8, 10, 12-21]. In the Game method for modelling theory several elements are necessary to be determined for starting the simulation: set of symbols $S$, an $n$-dimensional simplex, set of objects which are placed on the vertices on the simplex and a set of rules $A$. Each object is presented by its number, $n$-tuple of coordinates representing its location in the simplex, and a symbol from the set $S$ determining the specifications of the object. 
In our case the space is two-dimensional, the symbols are the natural numbers from 0 to 9 and they represent the quantity of wood mass per unit square.

The initial configuration is the combination of all ordered sets of $(n+2)$-tuples having as an initial component the identification number of the object; having the second, third, etc. component up to the $(n+1)$-st component being the object's coordinates; and the $(n+2)$-nd component being its symbol from the set $S$. The final configuration has the same format but after the procedure of modification during a given number of times when the rules from $A$ have been applied. An elementary step in the transformation of the model is the single application of a rule from $A$ over a given configuration $K$ and will be denoted by $A(K)$. In this sense, if $K$ is an initial configuration, and $L$ is a final configuration derived from $K$ through multiple application the rules from $A$, then configurations $K_{0}, K_{i}, \ldots, K_{m}$ will exist, for which:

$$
\begin{gathered}
K_{0}=K, \\
K_{i+1}=A_{1}\left(K_{i}\right), \text { for } 0<i<m-1, \\
K_{m}=L .
\end{gathered}
$$

The algorithm for applying the GMM is described in details in [1].

\section{Application of the game method for modelling for locating of the forest fire ignition point}

Below, we use as a basis our previous paper [11]. There, if some rule determines that symbol $B$ must be changed with symbol $C$, further we denote this fact by $B \rightarrow C$.

The rules for changing the digits during the fire:

A.1. $R \rightarrow R$;

A.2. $S \rightarrow S$;

A.3. $n \rightarrow n-1$, for $n \in[1,9]$;

A.4. $1 \rightarrow 0$.

Here $R$ denotes river, $S$ denotes rock or stones, and as was stated above the digits represent the quantity of wood mass (burning resource) per unit square.

On the first step, we take a field of the forested area in the form grid with the above denotations (configuration $K_{b}$ ). On the next step, we take the same field but with configuration $K_{a}$ after the fire has burned out. Then we build a configuration $D_{0}=K_{b}-K_{a}$. This configuration contains as elements digits corresponding to the quantity of burned wood mass. Using the above rules in stepwise manner from configuration $D_{0}$ we obtain subsequently configurations $D_{1}, D_{2}, \ldots$. This process of generating configurations ends when in the field remain only few squares containing the number 1. These squares are the potential ignition points of the fire. For each of them we determine its coordinates and after that for each of them we consider sequentially the initial 
configuration $K_{b}$ in which at the point with the respective coordinates a fire occurs. On this configuration we apply the following rules:

B.1. $R \rightarrow R$;

B.2. $S \rightarrow S$;

B.3. $0 \rightarrow 0$;

B.4. In the initial time-step, the fire starts from a fixed cell containing digit $n(1>n>9)$ that represents the density of the trees in the forest. On the second time-step for the same cell $n \rightarrow(n-1)$. On the third time-step for the same cell

$$
(n-1) \rightarrow \begin{cases}0, & \text { if } n=1 \\ n-2, & \text { if } n>1\end{cases}
$$

B.5. In the same moment all neighbour cells of the cell with the fire change their digits according to (2);

B.5. In the next moment all cells with fire change their digits by (2) and all their neighbouring cells in which there is no fire before the present moment, also change their digits according to $(2)$;

B.6. The process continues until all cells in the region contain only digit 0 . In the opposite case, go to B.5.

As a result for each potential ignition point with coordinates $(p, q)$ we obtain a final configuration $K_{f}(p, q)$ and we compare each of them to the configuration $K_{a}$. The one that resembles the most $\mathrm{Ka}$ in shape and value of digits corresponds to the most likely origin of fire.

Following [11], the cell in the configuration $K_{b}$ containing number 9 is a cell with highest quantity of wood mass before the fire. The field also contains cells marked with letters $R$ and $S$ used for determining the places with rivers (water) and stones or rocks (Fig. 1).

\begin{tabular}{|l|l|l|l|l|l|l|l|l|}
\hline 9 & 5 & 7 & 5 & 3 & 5 & 4 & 6 & 8 \\
\hline 8 & 6 & 7 & 6 & 5 & 4 & 5 & 7 & 7 \\
\hline 7 & 5 & 7 & 5 & 3 & $S$ & $S$ & 8 & 7 \\
\hline 6 & 4 & 6 & 5 & 4 & $S$ & $S$ & 7 & 8 \\
\hline 4 & 5 & 8 & 7 & 5 & 4 & 5 & 6 & 6 \\
\hline 5 & 3 & 4 & 3 & 2 & 7 & 9 & 8 & 7 \\
\hline 2 & 4 & 5 & 4 & 3 & 9 & $R$ & $R$ & $R$ \\
\hline 5 & 3 & 4 & 5 & 6 & 9 & $R$ & $R$ & $R$ \\
\hline 8 & 9 & 7 & 6 & 8 & $R$ & $R$ & 7 & 7 \\
\hline
\end{tabular}

Figure 1. Grid of cells in the initial configuration $K_{b}$ 


\begin{tabular}{|l|l|l|l|l|l|l|l|l|}
\hline 9 & 5 & 7 & 5 & 3 & 5 & 4 & 6 & 8 \\
\hline 8 & 4 & 3 & 3 & 0 & 1 & 2 & 4 & 7 \\
\hline 7 & 3 & 2 & 1 & 0 & $S$ & $S$ & 2 & 7 \\
\hline 6 & 2 & 3 & 0 & 0 & $S$ & $S$ & 3 & 8 \\
\hline 4 & 2 & 4 & 1 & 0 & 1 & 2 & 3 & 6 \\
\hline 5 & 2 & 0 & 0 & 0 & 3 & 5 & 4 & 7 \\
\hline 2 & 2 & 1 & 1 & 0 & 2 & $R$ & $R$ & $R$ \\
\hline 5 & 1 & 1 & 1 & 1 & 5 & $R$ & $R$ & $R$ \\
\hline 8 & 9 & 7 & 6 & 8 & $R$ & $R$ & 7 & 7 \\
\hline
\end{tabular}

Figure 2. Grid of cells in the final configuration $K_{a}$

The final configuration $K_{a}$ represents the same field after the fire. The affected cells by the forest fire contain the smaller digit or the number 0 . The cell with value 0 is a "dead cell" or the cell is devastated by the fire. The containing the letters $R$ and $S$ determine again the places with rivers (water) and stones or rocks, respectively, and they remain unchanged (Fig. 2).

For brevity, we assume that the fire region has the rectangular (square) form from Fig. 1 with 81 cells, but in the present case, the region in which there is fire contains 49 cells.

Let us define the TIFPs $\langle a(t), b(t)\rangle$ as follows:

- $a(t)$ is the number of cells of the region without fire in the time-moment $t$,

- $b(t)$ is the number of cells of the region in which the fire had burn totally the forest in the time-moment $t$.

Therefore, the number $1-a(t)-b(t)$ corresponds to the number of cells in which the fire continues to exist.

In [11], thereafter we transform the model to calculate the difference between the initial configuration $K_{b}$ and the final configuration $K_{a}$ to determine the configuration the fire damages $D_{0}$. The cells containing the digit " 0 " are the parts of the area that are not affected by the fire. For instance, the two cells containing 7 in the lower right corner of the field correspond to parts of the forest on the opposite of the river, which have remained undisturbed by the fire (cf. Figs. 1, 2 and 3). The cells containing values in the range of $[1,9]$ are devastated with different degrees of damages. The stones (or rocks) and rivers $(S$ and $R$ ) are cells that cannot be affected by the fire. The GMM over the area burned by the forest fire will be applied to detect the origin of the fire.

\begin{tabular}{|l|l|l|l|l|l|l|l|l|}
\hline 0 & 0 & 0 & 0 & 0 & 0 & 0 & 0 & 0 \\
\hline 0 & 2 & 4 & 3 & 5 & 3 & 3 & 3 & 0 \\
\hline 0 & 2 & 5 & 4 & 3 & $S$ & $S$ & 6 & 0 \\
\hline 0 & 2 & 3 & 5 & 4 & $S$ & $S$ & 4 & 0 \\
\hline 0 & 3 & 4 & 7 & 5 & 3 & 3 & 3 & 0 \\
\hline 0 & 1 & 4 & 3 & 2 & 4 & 4 & 4 & 0 \\
\hline 0 & 2 & 4 & 3 & 3 & 7 & $R$ & $R$ & $R$ \\
\hline 0 & 2 & 3 & 4 & 5 & 4 & $R$ & $R$ & $R$ \\
\hline 0 & 0 & 0 & 0 & 0 & $R$ & $R$ & 0 & 0 \\
\hline
\end{tabular}

Figure 3. Grid of cells in the configuration with the fire damages $D_{0}$ 
Here, we omit the steps of searching of the possible wild fire ignition points and show only the final result of this search - Fig. 4.

The application of the GMM over selected area determines two possible ignition points for locating the fire. Considered together these cells can be investigated as a single origin from which the fire has started, or that both ignition points have been activated simultaneously. Applying the rules $B$ described above we obtain the different final configurations as we discussed above. In this manner we determine the possible points of origin of forest fire.

\begin{tabular}{|l|l|l|l|l|l|l|l|l|}
\hline 0 & 0 & 0 & 0 & 0 & 0 & 0 & 0 & 0 \\
\hline 0 & 0 & 0 & 0 & 0 & 0 & 0 & 0 & 0 \\
\hline 0 & 0 & 0 & 0 & 0 & $S$ & $S$ & 1 & 0 \\
\hline 0 & 0 & 0 & 0 & 0 & $S$ & $S$ & 0 & 0 \\
\hline 0 & 0 & 0 & 0 & 0 & 0 & 0 & 0 & 0 \\
\hline 0 & 0 & 0 & 0 & 0 & 0 & 0 & 0 & 0 \\
\hline 0 & 0 & 0 & 0 & 0 & 1 & $R$ & $R$ & $R$ \\
\hline 0 & 0 & 0 & 0 & 0 & 0 & $R$ & $R$ & $R$ \\
\hline 0 & 0 & 0 & 0 & 0 & $R$ & $R$ & 0 & 0 \\
\hline
\end{tabular}

Figure 4. Grid of cells after the sixth iteration $D_{6}$

In the first case we consider that the fire is started form the cells with digit 8 form the ignition points from the previous example. The rules B will be applied over the grid of cells to obtain the final configurations comparable with the final configuration discussed above (Fig. 2). The initial configuration is presented (Fig. 5). Sixth iterations of the GMM are performed (Fig. 6 - Fig. 11). The resulting configuration (Fig. 11) is compared with the final configuration (Fig. 2) to find possible similarities. Obviously, there are two grid of cells that are not exactly the same. However, we can conclude that the resulting grids are congruent according to the half closest digits in the cells.

\begin{tabular}{|c|c|c|c|c|c|c|c|c|}
\hline 0 & 0 & 0 & 0 & 0 & 0 & 0 & 0 & 0 \\
\hline 0 & 6 & 7 & 6 & 5 & 4 & 5 & 7 & 0 \\
\hline 0 & 5 & 7 & 5 & 3 & $S$ & $S$ & 8 & 0 \\
\hline 0 & 4 & 6 & 5 & 4 & $S$ & $S$ & 7 & 0 \\
\hline 0 & 5 & 8 & 7 & 5 & 4 & 5 & 6 & 0 \\
\hline 0 & 3 & 4 & 3 & 2 & 7 & 9 & 8 & 0 \\
\hline 0 & 4 & 5 & 4 & 3 & 9 & $R$ & $R$ & $R$ \\
\hline 0 & 3 & 4 & 5 & 6 & 9 & $R$ & $R$ & $R$ \\
\hline 0 & 0 & 0 & 0 & 0 & $R$ & $R$ & 0 & 0 \\
\hline
\end{tabular}

Figure 5. Grid of cells after activating the first cell with a TIFP $\langle a(0), b(0)\rangle=\langle 40 / 49,0\rangle$ 


\begin{tabular}{|c|c|c|c|c|c|c|c|c|}
\hline 0 & 0 & 0 & 0 & 0 & 0 & 0 & 0 & 0 \\
\hline 0 & 6 & 7 & 6 & 5 & 4 & 5 & 7 & 0 \\
\hline 0 & 5 & 7 & 5 & 3 & $S$ & $S$ & 7 & 0 \\
\hline 0 & 4 & 6 & 5 & 4 & $S$ & $S$ & 7 & 0 \\
\hline 0 & 5 & 8 & 7 & 5 & 4 & 5 & 6 & 0 \\
\hline 0 & 3 & 4 & 3 & 2 & 7 & 9 & 8 & 0 \\
\hline 0 & 4 & 5 & 4 & 3 & 9 & $R$ & $R$ & $R$ \\
\hline 0 & 3 & 4 & 5 & 6 & 9 & $R$ & $R$ & $R$ \\
\hline 0 & 0 & 0 & 0 & 0 & $R$ & $R$ & 0 & 0 \\
\hline
\end{tabular}

Figure 6. Grid of cells after the activating the first cell-first iteration $E_{1}$ with a TIFP $\langle a(1), b(1)\rangle\langle a(1), b(1)\rangle=\langle 40 / 49,0\rangle$

\begin{tabular}{|c|c|c|c|c|c|c|c|c|}
\hline 0 & 0 & 0 & 0 & 0 & 0 & 0 & 0 & 0 \\
\hline 0 & 6 & 7 & 6 & 5 & 4 & 4 & 6 & 0 \\
\hline 0 & 5 & 7 & 5 & 3 & $S$ & $S$ & 6 & 0 \\
\hline 0 & 4 & 6 & 5 & 4 & $S$ & $S$ & 6 & 0 \\
\hline 0 & 5 & 8 & 7 & 5 & 4 & 5 & 6 & 0 \\
\hline 0 & 3 & 4 & 3 & 2 & 7 & 9 & 8 & 0 \\
\hline 0 & 4 & 5 & 4 & 3 & 9 & $R$ & $R$ & $R$ \\
\hline 0 & 3 & 4 & 5 & 6 & 9 & $R$ & $R$ & $R$ \\
\hline 0 & 0 & 0 & 0 & 0 & $R$ & $R$ & 0 & 0 \\
\hline
\end{tabular}

Figure 7. Grid of cells after the activating the first cell-second iteration $E_{2}$ with a TIFP $\langle a(2), b(2)\rangle=\langle 37 / 49,0\rangle$

\begin{tabular}{|c|c|c|c|c|c|c|c|c|}
\hline 0 & 0 & 0 & 0 & 0 & 0 & 0 & 0 & 0 \\
\hline 0 & 6 & 7 & 6 & 5 & 3 & 3 & 5 & 0 \\
\hline 0 & 5 & 7 & 5 & 3 & $S$ & $S$ & 5 & 0 \\
\hline 0 & 4 & 6 & 5 & 4 & $S$ & $S$ & 5 & 0 \\
\hline 0 & 5 & 8 & 7 & 5 & 4 & 4 & 5 & 0 \\
\hline 0 & 3 & 4 & 3 & 2 & 7 & 9 & 8 & 0 \\
\hline 0 & 4 & 5 & 4 & 3 & 9 & $R$ & $R$ & $R$ \\
\hline 0 & 3 & 4 & 5 & 6 & 9 & $R$ & $R$ & $R$ \\
\hline 0 & 0 & 0 & 0 & 0 & $R$ & $R$ & 0 & 0 \\
\hline
\end{tabular}

Figure 8. Grid of cells after the activating the first cell-third iteration $E_{3}$ with a $\operatorname{TIFP}\langle a(3), b(3)\rangle=\langle 34 / 49,0\rangle$ 


\begin{tabular}{|c|c|c|c|c|c|c|c|c|}
\hline 0 & 0 & 0 & 0 & 0 & 0 & 0 & 0 & 0 \\
\hline 0 & 6 & 7 & 6 & 4 & 2 & 2 & 4 & 0 \\
\hline 0 & 5 & 7 & 5 & 3 & $S$ & $S$ & 4 & 0 \\
\hline 0 & 4 & 6 & 5 & 4 & $S$ & $S$ & 4 & 0 \\
\hline 0 & 5 & 8 & 7 & 5 & 3 & 3 & 4 & 0 \\
\hline 0 & 3 & 4 & 3 & 2 & 6 & 8 & 7 & 0 \\
\hline 0 & 4 & 5 & 4 & 3 & 9 & $R$ & $R$ & $R$ \\
\hline 0 & 3 & 4 & 5 & 6 & 9 & $R$ & $R$ & $R$ \\
\hline 0 & 0 & 0 & 0 & 0 & $R$ & $R$ & 0 & 0 \\
\hline
\end{tabular}

Figure 9. Grid of cells after the activating the first cell-fourth iteration $E_{4}$ with a $\operatorname{TIFP}\langle a(4), b(4)\rangle=\langle 29 / 81,0\rangle$

\begin{tabular}{|c|c|c|c|c|c|c|c|c|}
\hline 0 & 0 & 0 & 0 & 0 & 0 & 0 & 0 & 0 \\
\hline 0 & 6 & 7 & 5 & 3 & 1 & 1 & 3 & 0 \\
\hline 0 & 5 & 7 & 4 & 2 & $S$ & $S$ & 3 & 0 \\
\hline 0 & 4 & 6 & 5 & 3 & $S$ & $S$ & 3 & 0 \\
\hline 0 & 5 & 8 & 7 & 4 & 2 & 2 & 3 & 0 \\
\hline 0 & 3 & 4 & 3 & 1 & 5 & 7 & 6 & 0 \\
\hline 0 & 4 & 5 & 4 & 2 & 8 & $R$ & $R$ & $R$ \\
\hline 0 & 3 & 4 & 5 & 6 & 9 & $R$ & $R$ & $R$ \\
\hline 0 & 0 & 0 & 0 & 0 & $R$ & $R$ & 0 & 0 \\
\hline
\end{tabular}

Figure 10. Grid of cells after the activating the first cell-fifth iteration $E_{5}$ with a TIFP $\langle a(5), b(5)\rangle=\langle 21 / 49,0\rangle$

\begin{tabular}{|c|c|c|c|c|c|c|c|c|}
\hline 0 & 0 & 0 & 0 & 0 & 0 & 0 & 0 & 0 \\
\hline 0 & 6 & 6 & 4 & 2 & 0 & 0 & 2 & 0 \\
\hline 0 & 5 & 6 & 3 & 1 & $S$ & $S$ & 2 & 0 \\
\hline 0 & 4 & 5 & 4 & 2 & $S$ & $S$ & 2 & 0 \\
\hline 0 & 5 & 8 & 6 & 3 & 1 & 1 & 2 & 0 \\
\hline 0 & 3 & 4 & 2 & 0 & 4 & 6 & 5 & 0 \\
\hline 0 & 4 & 5 & 3 & 1 & 7 & $R$ & $R$ & $R$ \\
\hline 0 & 3 & 4 & 4 & 5 & 8 & $R$ & $R$ & $R$ \\
\hline 0 & 0 & 0 & 0 & 0 & $R$ & $R$ & 0 & 0 \\
\hline
\end{tabular}

Figure 11. Grid of cells after the activating the first cell-sixth iteration $E_{6}$ with a $\operatorname{TIFP}\langle a(6), b(6)\rangle=\langle 11 / 49,3 / 49\rangle$ 
In the second case the fire begins from the ignition point containing the digit 9 (Fig. 12). GMM will be applied to determine the possible damages of the fire (Fig. 13-19).

\begin{tabular}{|c|c|c|c|c|c|c|c|c|}
\hline 0 & 0 & 0 & 0 & 0 & 0 & 0 & 0 & 0 \\
\hline 0 & 6 & 7 & 6 & 5 & 4 & 5 & 7 & 0 \\
\hline 0 & 5 & 7 & 5 & 3 & $S$ & $S$ & 8 & 0 \\
\hline 0 & 4 & 6 & 5 & 4 & $S$ & $S$ & 7 & 0 \\
\hline 0 & 5 & 8 & 7 & 5 & 4 & 5 & 6 & 0 \\
\hline 0 & 3 & 4 & 3 & 2 & 7 & 9 & 8 & 0 \\
\hline 0 & 4 & 5 & 4 & 3 & 9 & $R$ & $R$ & $R$ \\
\hline 0 & 3 & 4 & 5 & 6 & 9 & $R$ & $R$ & $R$ \\
\hline 0 & 0 & 0 & 0 & 0 & $R$ & $R$ & 0 & 0 \\
\hline
\end{tabular}

Figure 12. Grid of cells after activating the second cell with a TIFP $\langle c(0), d(0)\rangle=\langle 40 / 49,0\rangle$

\begin{tabular}{|c|c|c|c|c|c|c|c|c|}
\hline 0 & 0 & 0 & 0 & 0 & 0 & 0 & 0 & 0 \\
\hline 0 & 6 & 7 & 6 & 5 & 4 & 5 & 7 & 0 \\
\hline 0 & 5 & 7 & 5 & 3 & $S$ & $S$ & 8 & 0 \\
\hline 0 & 4 & 6 & 5 & 4 & $S$ & $S$ & 7 & 0 \\
\hline 0 & 5 & 8 & 7 & 5 & 4 & 5 & 6 & 0 \\
\hline 0 & 3 & 4 & 3 & 2 & 7 & 9 & 8 & 0 \\
\hline 0 & 4 & 5 & 4 & 3 & 8 & $R$ & $R$ & $R$ \\
\hline 0 & 3 & 4 & 5 & 6 & 9 & $R$ & $R$ & $R$ \\
\hline 0 & 0 & 0 & 0 & 0 & $R$ & $R$ & 0 & 0 \\
\hline
\end{tabular}

Figure 13. Grid of cells after the activating the second cell-first iteration $F_{1}$ with a $\operatorname{TIFP}\langle c(1), d(1)\rangle=\langle 40 / 49,0\rangle$

\begin{tabular}{|c|c|c|c|c|c|c|c|c|}
\hline 0 & 0 & 0 & 0 & 0 & 0 & 0 & 0 & 0 \\
\hline 0 & 6 & 7 & 6 & 5 & 4 & 5 & 7 & 0 \\
\hline 0 & 5 & 7 & 5 & 3 & $S$ & $S$ & 8 & 0 \\
\hline 0 & 4 & 6 & 5 & 4 & $S$ & $S$ & 7 & 0 \\
\hline 0 & 5 & 8 & 7 & 5 & 4 & 5 & 6 & 0 \\
\hline 0 & 3 & 4 & 3 & 1 & 6 & 8 & 8 & 0 \\
\hline 0 & 4 & 5 & 4 & 2 & 7 & $R$ & $R$ & $R$ \\
\hline 0 & 3 & 4 & 5 & 5 & 8 & $R$ & $R$ & $R$ \\
\hline 0 & 0 & 0 & 0 & 0 & $R$ & $R$ & 0 & 0 \\
\hline
\end{tabular}

Figure 14. Grid of cells after the activating the second cell-second iteration $F_{2}$ with a TIFP $\langle c(2), d(2)\rangle=\langle 34 / 49,0\rangle$ 


\begin{tabular}{|l|l|l|l|l|l|l|l|l|}
\hline 0 & 0 & 0 & 0 & 0 & 0 & 0 & 0 & 0 \\
\hline 0 & 6 & 7 & 6 & 5 & 4 & 5 & 7 & 0 \\
\hline 0 & 5 & 7 & 5 & 3 & $S$ & $S$ & 8 & 0 \\
\hline 0 & 4 & 6 & 5 & 4 & $S$ & $S$ & 7 & 0 \\
\hline 0 & 5 & 8 & 6 & 4 & 3 & 4 & 5 & 0 \\
\hline 0 & 3 & 4 & 2 & 0 & 5 & 7 & 7 & 0 \\
\hline 0 & 4 & 5 & 3 & 1 & 6 & $R$ & $R$ & $R$ \\
\hline 0 & 3 & 4 & 4 & 4 & 7 & $R$ & $R$ & $R$ \\
\hline 0 & 0 & 0 & 0 & 0 & $R$ & $R$ & 0 & 0 \\
\hline
\end{tabular}

Figure 15. Grid of cells after the activating the second cell-third iteration $F_{3}$ with a TIFP $\langle c(3), d(3)\rangle=\langle 25 / 49,1 / 49\rangle$

\begin{tabular}{|l|l|l|l|l|l|l|l|l|}
\hline 0 & 0 & 0 & 0 & 0 & 0 & 0 & 0 & 0 \\
\hline 0 & 6 & 7 & 6 & 5 & 4 & 5 & 7 & 0 \\
\hline 0 & 5 & 7 & 5 & 3 & $S$ & $S$ & 8 & 0 \\
\hline 0 & 4 & 5 & 4 & 3 & $S$ & $S$ & 6 & 0 \\
\hline 0 & 5 & 7 & 5 & 3 & 2 & 3 & 4 & 0 \\
\hline 0 & 3 & 3 & 1 & 0 & 4 & 6 & 6 & 0 \\
\hline 0 & 4 & 4 & 2 & 0 & 5 & $R$ & $R$ & $R$ \\
\hline 0 & 3 & 3 & 3 & 3 & 6 & $R$ & $R$ & $R$ \\
\hline 0 & 0 & 0 & 0 & 0 & $R$ & $R$ & 0 & 0 \\
\hline
\end{tabular}

Figure 16. Grid of cells after the activating the second cell-fourth iteration $F_{4}$ with a $\operatorname{TIFP}\langle c(4), d(4)\rangle=\langle 17 / 49,2 / 49\rangle$

\begin{tabular}{|l|l|l|l|l|l|l|l|l|}
\hline 0 & 0 & 0 & 0 & 0 & 0 & 0 & 0 & 0 \\
\hline 0 & 6 & 7 & 6 & 5 & 4 & 5 & 7 & 0 \\
\hline 0 & 4 & 6 & 4 & 2 & $S$ & $S$ & 7 & 0 \\
\hline 0 & 3 & 4 & 3 & 2 & $S$ & $S$ & 5 & 0 \\
\hline 0 & 4 & 6 & 4 & 2 & 1 & 2 & 3 & 0 \\
\hline 0 & 2 & 2 & 0 & 0 & 3 & 5 & 5 & 0 \\
\hline 0 & 3 & 3 & 1 & 0 & 4 & $R$ & $R$ & $R$ \\
\hline 0 & 2 & 2 & 2 & 2 & 5 & $R$ & $R$ & $R$ \\
\hline 0 & 0 & 0 & 0 & 0 & $R$ & $R$ & 0 & 0 \\
\hline
\end{tabular}

Figure 17. Grid of cells after the activating the second cell-fifth iteration $F_{5}$ with a $\operatorname{TIFP}\langle c(5), d(5)\rangle=\langle 7 / 49,3 / 49\rangle$ 


\begin{tabular}{|c|c|c|c|c|c|c|c|c|}
\hline 0 & 0 & 0 & 0 & 0 & 0 & 0 & 0 & 0 \\
\hline 0 & 5 & 6 & 5 & 4 & 3 & 4 & 6 & 0 \\
\hline 0 & 3 & 5 & 3 & 1 & $S$ & $S$ & 6 & 0 \\
\hline 0 & 2 & 3 & 2 & 1 & $S$ & $S$ & 4 & 0 \\
\hline 0 & 3 & 5 & 3 & 1 & 0 & 1 & 2 & 0 \\
\hline 0 & 1 & 1 & 0 & 0 & 2 & 4 & 4 & 0 \\
\hline 0 & 2 & 2 & 0 & 0 & 3 & $R$ & $R$ & $R$ \\
\hline 0 & 1 & 1 & 1 & 1 & 4 & $R$ & $R$ & $R$ \\
\hline 0 & 0 & 0 & 0 & 0 & $R$ & $R$ & 0 & 0 \\
\hline
\end{tabular}

Figure 18. Grid of cells after the activating the second cell-sixth iteration $F_{6}$ with a TIFP $\langle c(6), d(6)\rangle=\langle 0,5 / 49\rangle$

\begin{tabular}{|c|c|c|c|c|c|c|c|c|}
\hline 0 & 0 & 0 & 0 & 0 & 0 & 0 & 0 & 0 \\
\hline 0 & 4 & 5 & 4 & 3 & 2 & 3 & 5 & 0 \\
\hline 0 & 2 & 4 & 2 & 0 & $S$ & $S$ & 5 & 0 \\
\hline 0 & 1 & 2 & 1 & 0 & $S$ & $S$ & 3 & 0 \\
\hline 0 & 2 & 4 & 2 & 0 & 0 & 0 & 1 & 0 \\
\hline 0 & 0 & 0 & 0 & 0 & 1 & 3 & 3 & 0 \\
\hline 0 & 1 & 1 & 0 & 0 & 2 & $R$ & $R$ & $R$ \\
\hline 0 & 0 & 0 & 0 & 0 & 3 & $R$ & $R$ & $R$ \\
\hline 0 & 0 & 0 & 0 & 0 & $R$ & $R$ & 0 & 0 \\
\hline
\end{tabular}

Figure 19. Grid of cells after the activating the second cell-seventh iteration $F_{7}$ with a TIFP $\langle c(7), d(7)\rangle=\langle 0,15 / 49\rangle$

The resulting configuration of the presented simulation is more similar to the final configuration of the first application (Fig. 2). The digits of the cells are the same or similar. The ignition point with the digit 9 presents more accurate model of the spread of fire.

In the third case the fire can be started with two ignition points simultaneously. The process of the spread of fire will be simulated using GMM in the six steps.

In the current investigation we will consider the purpose of the fire beginning form two cells (Fig. 20). They will be activated and the spread of fire will be modeled. Six steps will be used to apply GMM (Fig. 21 - Fig. 26). Firstly, the ignition points are activated. In the second step the neighbors of the "alive" cells are launched. In the next steps the process is repeated. 


\begin{tabular}{|c|c|c|c|c|c|c|c|c|}
\hline 0 & 0 & 0 & 0 & 0 & 0 & 0 & 0 & 0 \\
\hline 0 & 6 & 7 & 6 & 5 & 4 & 5 & 7 & 0 \\
\hline 0 & 5 & 7 & 5 & 3 & $S$ & $S$ & 8 & 0 \\
\hline 0 & 4 & 6 & 5 & 4 & $S$ & $S$ & 7 & 0 \\
\hline 0 & 5 & 8 & 7 & 5 & 4 & 5 & 6 & 0 \\
\hline 0 & 3 & 4 & 3 & 2 & 7 & 9 & 8 & 0 \\
\hline 0 & 4 & 5 & 4 & 3 & 9 & $R$ & $R$ & $R$ \\
\hline 0 & 3 & 4 & 5 & 6 & 9 & $R$ & $R$ & $R$ \\
\hline 0 & 0 & 0 & 0 & 0 & $R$ & $R$ & 0 & 0 \\
\hline
\end{tabular}

Figure 20. Grid of cells before spread of fire with a TIFP $\langle e(0), f(0)\rangle=\langle 39 / 49,0\rangle$

\begin{tabular}{|c|c|c|c|c|c|c|c|c|}
\hline 0 & 0 & 0 & 0 & 0 & 0 & 0 & 0 & 0 \\
\hline 0 & 6 & 7 & 6 & 5 & 4 & 5 & 7 & 0 \\
\hline 0 & 5 & 7 & 5 & 3 & $S$ & $S$ & 7 & 0 \\
\hline 0 & 4 & 6 & 5 & 4 & $S$ & $S$ & 7 & 0 \\
\hline 0 & 5 & 8 & 7 & 5 & 4 & 5 & 6 & 0 \\
\hline 0 & 3 & 4 & 3 & 2 & 7 & 9 & 8 & 0 \\
\hline 0 & 4 & 5 & 4 & 3 & 8 & $R$ & $R$ & $R$ \\
\hline 0 & 3 & 4 & 5 & 6 & 9 & $R$ & $R$ & $R$ \\
\hline 0 & 0 & 0 & 0 & 0 & $R$ & $R$ & 0 & 0 \\
\hline
\end{tabular}

Figure 21. Grid of cells after the activating the first and the second cell-first iteration $G_{1}$ with a TIFP $\langle e(1), f(1)\rangle=\langle 39 / 49,0\rangle$

\begin{tabular}{|l|l|l|l|l|l|l|l|l|}
\hline 0 & 0 & 0 & 0 & 0 & 0 & 0 & 0 & 0 \\
\hline 0 & 6 & 7 & 6 & 5 & 4 & 4 & 6 & 0 \\
\hline 0 & 5 & 7 & 5 & 3 & $S$ & $S$ & 6 & 0 \\
\hline 0 & 4 & 6 & 5 & 4 & $S$ & $S$ & 6 & 0 \\
\hline 0 & 5 & 8 & 7 & 5 & 4 & 5 & 6 & 0 \\
\hline 0 & 3 & 4 & 3 & 1 & 6 & 8 & 8 & 0 \\
\hline 0 & 4 & 5 & 4 & 2 & 7 & $R$ & $R$ & $R$ \\
\hline 0 & 3 & 4 & 5 & 5 & 8 & $R$ & $R$ & $R$ \\
\hline 0 & 0 & 0 & 0 & 0 & $R$ & $R$ & 0 & 0 \\
\hline
\end{tabular}

Figure 22. Grid of cells after the activating the first and the second cell-second iteration $G_{2}$ with a $\operatorname{TIFP}\langle e(2), f(2)\rangle=\langle 30 / 49,0\rangle$ 


\begin{tabular}{|l|l|l|l|l|l|l|l|l|}
\hline 0 & 0 & 0 & 0 & 0 & 0 & 0 & 0 & 0 \\
\hline 0 & 6 & 7 & 6 & 5 & 3 & 3 & 5 & 0 \\
\hline 0 & 5 & 7 & 5 & 3 & $S$ & $S$ & 5 & 0 \\
\hline 0 & 4 & 6 & 5 & 4 & $S$ & $S$ & 5 & 0 \\
\hline 0 & 5 & 8 & 6 & 4 & 3 & 4 & 5 & 0 \\
\hline 0 & 3 & 4 & 2 & 0 & 5 & 7 & 8 & 0 \\
\hline 0 & 4 & 5 & 3 & 1 & 6 & $R$ & $R$ & $R$ \\
\hline 0 & 3 & 4 & 4 & 4 & 7 & $R$ & $R$ & $R$ \\
\hline 0 & 0 & 0 & 0 & 0 & $R$ & $R$ & 0 & 0 \\
\hline
\end{tabular}

Figure 23. Grid of cells after the activating the first and the second cell-third iteration $G_{3}$ with a TIFP $\langle e(3), f(3)\rangle=\langle 20 / 49,1 / 49\rangle$

\begin{tabular}{|l|l|l|l|l|l|l|l|l|}
\hline 0 & 0 & 0 & 0 & 0 & 0 & 0 & 0 & 0 \\
\hline 0 & 6 & 7 & 6 & 4 & 2 & 2 & 4 & 0 \\
\hline 0 & 5 & 7 & 5 & 3 & $S$ & $S$ & 4 & 0 \\
\hline 0 & 4 & 5 & 4 & 3 & $S$ & $S$ & 4 & 0 \\
\hline 0 & 5 & 7 & 5 & 3 & 2 & 3 & 4 & 0 \\
\hline 0 & 3 & 3 & 1 & 0 & 4 & 6 & 7 & 0 \\
\hline 0 & 4 & 4 & 2 & 0 & 5 & $R$ & $R$ & $R$ \\
\hline 0 & 3 & 3 & 3 & 3 & 6 & $R$ & $R$ & $R$ \\
\hline 0 & 0 & 0 & 0 & 0 & $R$ & $R$ & 0 & 0 \\
\hline
\end{tabular}

Figure 24. Grid of cells after the activating the first and the second cell-fourth iteration $G_{4}$ with a TIFP $\langle e(4), f(4)\rangle=\langle 12 / 49,2 / 49\rangle$

\begin{tabular}{|l|l|l|l|l|l|l|l|l|}
\hline 0 & 0 & 0 & 0 & 0 & 0 & 0 & 0 & 0 \\
\hline 0 & 6 & 7 & 5 & 3 & 1 & 1 & 3 & 0 \\
\hline 0 & 4 & 6 & 4 & 2 & $S$ & $S$ & 3 & 0 \\
\hline 0 & 3 & 4 & 3 & 2 & $S$ & $S$ & 3 & 0 \\
\hline 0 & 4 & 6 & 4 & 2 & 1 & 2 & 3 & 0 \\
\hline 0 & 2 & 2 & 0 & 0 & 3 & 5 & 6 & 0 \\
\hline 0 & 3 & 3 & 1 & 0 & 4 & $R$ & $R$ & $R$ \\
\hline 0 & 2 & 2 & 2 & 2 & 5 & $R$ & $R$ & $R$ \\
\hline 0 & 0 & 0 & 0 & 0 & $R$ & $R$ & 0 & 0 \\
\hline
\end{tabular}

Figure 25. Grid of cells after the activating the first and the second cell-fifth iteration $G_{5}$ with a TIFP $\langle e(5), f(5)\rangle=\langle 2 / 49,3 / 49\rangle$ 


\begin{tabular}{|c|c|c|c|c|c|c|c|c|}
\hline 0 & 0 & 0 & 0 & 0 & 0 & 0 & 0 & 0 \\
\hline 0 & 5 & 6 & 4 & 2 & 0 & 0 & 2 & 0 \\
\hline 0 & 3 & 5 & 3 & 1 & $S$ & $S$ & 2 & 0 \\
\hline 0 & 2 & 3 & 2 & 1 & $S$ & $S$ & 2 & 0 \\
\hline 0 & 3 & 5 & 3 & 1 & 0 & 1 & 2 & 0 \\
\hline 0 & 1 & 1 & 0 & 0 & 2 & 4 & 5 & 0 \\
\hline 0 & 2 & 2 & 0 & 0 & 3 & $R$ & $R$ & $R$ \\
\hline 0 & 1 & 1 & 1 & 1 & 4 & $R$ & $R$ & $R$ \\
\hline 0 & 0 & 0 & 0 & 0 & $R$ & $R$ & 0 & 0 \\
\hline
\end{tabular}

Figure 26. Grid of cells after the activating the first and the second cell-sixth iteration $G_{6}$ with a TIFP $\langle e(6), f(6)\rangle=\langle 0,7 / 49\rangle$

The third case of the modeling of the spread of fire is the more similar to the final configuration of the forest fire (Fig. 2). The digits for the grid of cells are the closest with the values in the final configuration of the presented forest fire case. The fire develops smoothly and evenly. Thus, in a stepwise manner we construct the model of the given process.

More formally, if $s_{i j}^{p}$ is the number standing in the cell with coordinates $(i, j)$ in the configuration $K_{p}$, then the difference between two configurations $K_{1}$ and $K_{2}$ can be estimated as

$$
\mathrm{d}\left(K_{1}, K_{2}\right)=\sum_{i, j}\left|s_{i j}^{1}-s_{i j}^{2}\right|
$$

Then, as it is mentioned in [11], we obtain

$$
\begin{aligned}
& \mathrm{d}\left(K_{a}, E_{7}\right)=83, \\
& \mathrm{~d}\left(K_{a}, F_{7}\right)=48, \\
& \mathrm{~d}\left(K_{a}, G_{6}\right)=38 .
\end{aligned}
$$

The concrete configuration $K_{a}$ (Fig. 2) shows as a most possibility the situation with two simultaneous fires in the red points in configuration $D_{6}$ (Fig. 4).

Here, using the TIFPs, we can see that the results are respectively:

$$
\begin{gathered}
\langle a(7), b(7)\rangle=\langle 11 / 49,3 / 49\rangle, \\
\langle c(7), d(7)\rangle=\langle 0,15 / 49\rangle, \\
\langle e(6), f(6)\rangle=\langle 0,7 / 49\rangle .
\end{gathered}
$$

The TIFP, that corresponds to the region from Fig. 2 is $\langle p, q\rangle=\langle 0,9 / 49\rangle$, which again shows as a most possibility the situation with two simultaneous fires. 


\section{Conclusions and further research}

Another possibility for representing the field is by using regular hexagons. In this case for the described above process before and after the fire the configurations will be as given in Fig. 27. In a future work we will describe the rules by which from Fig. 27 we can search for the potential ignition points of the fire.
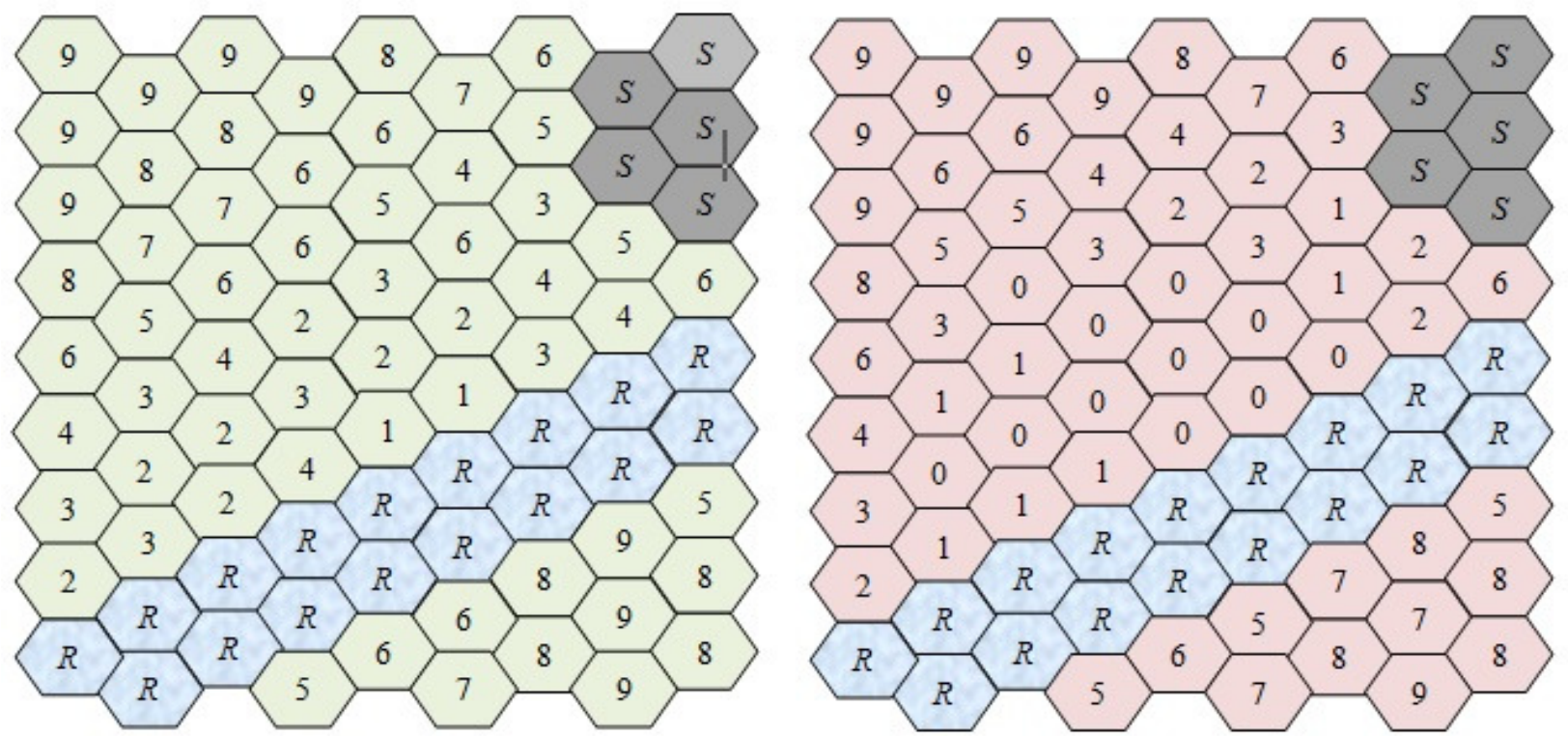

Figure 27. Initial configiuration - left side and final configuration - right side of the hexagonal grid of cells

In the future rules will be constructed for square and hexagonal cases which take into account situations including presence of wind, terrains with different slopes and other factors relevant to the fire generation.

In this new form of cells, TIFPs will be calculated, too.

\section{Acknowledgements}

The authors are grateful for the support provided by Grant DN16/6/2017 "Integrated Approach for Modeling of the Forest Fires Spread", funded by the Bulgarian National Science Fund.

\section{References}

[1] Atanassov, K. (2011). Game Method for Modelling. "Prof. M. Drinov" Academic Publishing House, Sofia.

[2] Atanassov, K. Intuitionistic Fuzzy Sets. Springer, Heidelberg, 1999.

[3] Atanassov, K. On Intuitionistic Fuzzy Sets Theory, Springer, Berlin, 2012. 
[4] Atanassov, K. Temporal intuitionistic fuzzy pairs. Proceedings of the Jangjeon Mathematical Society (in press).

[5] Atanassov, K., \& Sotirova, E. (2013). On some applications of game method for modeling, Part 4: Interpretations of some stochastic processes. Proceedings of the Jangjeon Mathematical Society, 16 (3), 301-310.

[6] Atanassov, K., E. Szmidt, J. Kacprzyk, On intuitionistic fuzzy pairs, Notes on Intuitionistic Fuzzy Sets, Vol. 19, 2013, No. 3, 1-13.

[7] Atanassova, L., \& Atanassov, K. (2011). Intuitionistic fuzzy interpretations of Conway's game of life. Lecture Notes in Computer Science, Vol. 6046, Springer, Berlin, 232-239.

[8] Atanassova, L., \& Atanassov, K. (2013). On a Game-Method for Modeling with Intuitionistic Fuzzy Estimations. Part 2. Monte Carlo Methods and Applications (K. Sabelfeld and I. Dimov, Eds.), Walter de Gruyter GmbH, Berlin/Boston, 29-38.

[9] Atanassova, L., Atanassov, K. (2012). On a game-method for modelling with intuitionistic fuzzy estimations: Part 1, Lecture Notes in Computer Science (including subseries Lecture Notes in Artificial Intelligence and Lecture Notes in Bioinformatics), Vol. 7116, 182-189.

[10] Beighley, M., \& Hyde, A. (2018). Portugal Wildfire Management in a New Era Assessing Fire Risks, Resources and Reforms, Instituto Superior D Agronomia, Universidade de Lisboa. Available online at: https://www.isa.ulisboa.pt/files/cef/pub/ articles/2018-04/2018_Portugal_Wildfire_Management_in_a_New_Era_ Engish.pdf

[11] Bureva, V., L. Atanassova, K. Atanassov, A. Delkov. Application of the game method for modelling for locating the wildfire ignition point. In:- Proceedings of 4th Int. Conf. on Numerical and Symbolic Computation, Porto, April, 11-12, 2019, 397-413.

[12] Dimitrov, D. (1998). Modelling the growth and dynamics of forest stands by game-method. Advances in Modelling \& Analysis, 2 (1-2), 11-22.

[13] Dimitrov, D. (1999). Modelling the growth and dynamics of forest stands by extended game-method. Advances in Modelling \& Analysis, 4 (1-2), 7-21.

[14] Gardner, M. (1970). Mathematical Games - The fantastic combinations of John Conway's new solitaire game "life". Scientific American, 223, 120-123.

[15] National Wildfire Coordinating Group (2016). Guide to Wildland Fire Origin and Cause Determination, PMS 412, NFES 1874. Available online at: https://www.nwcg.gov/ sites/default/files/publications/pms412.pdf

[16] San-Miguel-Ayanz, J., Durrant, T., Boca, R., Libertà, G., Branco, A., de Rigo, D., Ferrari, D., Maianti, P., Artés Vivancos, T., Costa, H., Lana, F., Löffler, P., Nuijten, D., Ahlgren, A. C., \& Leray; T. (2018). Forest Fires in Europe, Middle East and North Africa 2017. JRC Technical Report EUR 29318 EN, ISBN 978-92-79-92831-4, doi: 10.2760/663443.

[17] Sotirova, E., Bureva, V., Velizarova, E., Fidanova, S., Marinov, P., Shannon. A., \& Atanassov, K. (2013). Hexagonal Game Method model of forest fire spread with intuitionistic fuzzy estimations. Notes on Intuitionistic Fuzzy Sets, 19(3), 73-80. 
[18] Sotirova, E., Atanassov, K., Fidanova, S., Velizarova, E., Vassilev, P., \& Shannon, A. (2012). Application of the game method for modelling the forest fire perimeter expansion. Part 1: A model fire intensity without effect of wind, Proc. of IFAC Workshop on Dynamics and Control in Agriculture and Food Processing, Plovdiv, 13-16 June 2012, 159-163.

[19] Sotirova, E., Atanassov, K., Fidanova, S., Velizarova, E., Vassilev, P., \& Shannon, A. (2012). Application of the game method for modelling the forest fire perimeter expansion. Part 2: A model fire intensity with effect of wind, Proc. of IFAC Workshop on Dynamics and Control in Agriculture and Food Processing, Plovdiv, 13-16 June 2012, 165-169.

[20] Sotirova, E., Atanassov, K., Fidanova, S., Velizarova, E., Vassilev, P., \& Shannon, A. (2012). Application of the game method for modelling the forest fire perimeter expansion. Part 3: A model of the forest fire speed propagation in different homogenous vegetation types. Proc. of IFAC Workshop on Dynamics and Control in Agriculture and Food Processing, Plovdiv, 13-16 June 2012, 171-174.

[21] Sotirova, E., Dimitrov, D. \& Atanassov, K. (2012). On some applications of game method for modelling Part 1: Forest dynamics. Proceedings of the Jangjeon Mathematical Society, 15(2), 115-123.

[22] Sotirova, E., Dobrinkova, N., \& Atanassov, K. (2012). On some applications of game method for modeling. Part 2: Development of forest fire. Proceedings of the Jangjeon Mathematical Society, 15(3), 335-342.

[23] Sotirova, E., Sotirov, S., Atanassova, L., Atanassov, K. T., Bureva, V., \& Doukovska, L. (2018). Game Method for Modelling with Intuitionistic Fuzzy Rules. In: Atanassov K. et al. (eds) Uncertainty and Imprecision in Decision Making and Decision Support: CrossFertilization, New Models and Applications. Series Advances in Intelligent Systems and Computing, Springer, Vol 559, 153-168.

[24] Sotirova, E., Sotirov, S., Dimitrov, A., \& Atanassov, K. (2013). On some applications of the game method for modelling: Part 3: Simulation of oil transformation in marine environment. Proceedings of the Jangjeon Mathematical Society, 16(2), 293-300.

[25] Sotirova, E., Velizarova, E., Fidanova, S., \& Atanassov, K. (2014). Modeling forest fire spread through a game method for modeling based on hexagonal cells. Lecture Notes in Computer Science, Lecture Notes in Artificial Intelligence and Lecture Notes in Bioinformatics, 8353, 321-328.

[26] Velizarova, E., Sotirova, E., Atanassov, K., Vassilev, P., \& Fidanova, S. (2012). On the game method for the forest fire spread modelling with considering the wind effect. Proc. of 6th IEEE International Conference Intelligent Systems, art. no. 6335219, 216-220. 